University of Wollongong

Research Online

Faculty of Business - Papers (Archive)

Faculty of Business and Law

2013

A comparison of supply integration and end-to-end communication theory and practice - an Australian perspective

Fadi Kotob

University of Wollongong, fadik@uow.edu.au

Lee Styger

University of Wollongong, Istyger@uow.edu.au

Follow this and additional works at: https://ro.uow.edu.au/buspapers

Part of the Business Commons

Research Online is the open access institutional repository for the University of Wollongong. For further information contact the UOW Library: research-pubs@uow.edu.au 


\title{
A comparison of supply integration and end-to-end communication theory and practice - an Australian perspective
}

\begin{abstract}
The concept of supply chain integration and end-to-end communication are well established in supply chain theory. Typically, because of the depth of publications, an axiom has developed that all supply networks are fully integrated and have end-to-end communication protocols. Recent research into Australian supply networks has highlighted a somewhat different scenario, where many networks are fragmented and lack the connectivity that would be expected. This paper offers a comparison of theoretical supply chain management and the actual practices found in Australian businesses. As a result of this grass root research, a scenario is offered that suggest there is a significant gap between the theory and practice of supply integration and communication that in turn, generate risk in these supply networks.
\end{abstract}

\section{Keywords}

australian, perspective, supply, comparison, integration, end, communication, theory, practice

Disciplines

Business

\section{Publication Details}

Kotob, F. \& Styger, L. (2013). A comparison of supply integration and end-to-end communication theory and practice - an Australian perspective. World Journal of Social Sciences, 3 (4), 84-99. 


\title{
A Comparison of Supply Integration and End-To-End Communication Theory and Practice - An Australian Perspective
}

\begin{abstract}
Fadi Kotob* and Lee E J Styger**
The concept of supply chain integration and end-to-end communication are well established in supply chain theory. Typically, because of the depth of publications, an axiom has developed that all supply networks are fully integrated and have end-to-end communication protocols. Recent research into Australian supply networks has highlighted a somewhat different scenario, where many networks are fragmented and lack the connectivity that would be expected. This paper offers a comparison of theoretical supply chain management and the actual practices found in Australian businesses. As a result of this grass root research, a scenario is offered that suggest there is a significant gap between the theory and practice of supply integration and communication that in turn, generate risk in these supply networks.
\end{abstract}

Field of Research: Operations Management, Supply Chain Management, Communication

\section{Introduction}

There has been much speculation regarding the sustainability and innovation readiness of the Australian supply base in recent times. Alongside standard issues such as globalisation and diminishing traditional markets, more recent impacts of the Global Financial Crisis have undermined robust supply networks. In an attempt to provide some basic data concerning the Australian supply base, a program of work was conducted in 2010 to establish the resilience of grass root supply networks in Australia. A series of focus group workshops and face-to-face interviews with industry practitioners resulted in a picture of Australian supply networks that did not fit well with current theoretical constructs. The focus groups were conducted in:

- Sydney

- Melbourne

- Perth

- Darwin

- Brisbane

- Rockhampton

This paper provides a comparison between current supply theory and actual practices within the Australian context. It is suggested that an embedded hierarchical network protocol in many supply networks has limited visibility and communication within these networks, causing risks to be embedded within the

\footnotetext{
*Mr. Fadi Kotob, Sydney Business School, University of Wollongong, Australia.Email : fadik@uow.edu.au

${ }^{* *}$ Dr. Lee E J Styger, Sydney Business School, University of Wollongong, Australia.Email : Istyger@uow.edu.au
} 


\section{Kotob \& Styger}

network that could lead to greater gaps between theory and practice into the future. The limitation of specific region and/or sector studies is that they could typically focus on the main interaction node within a supply network, but lose site of seemingly unimportant lower level suppliers. An assumption often used in commercial supply chain studies and mapping exercises is that lower level suppliers have little effect in the overall competitive and operational readiness of a supply network. However, if the data from this study is extrapolated, then it becomes apparent that most of the supply base could be significantly below the performance capability necessary to sustain supply networks throughout Australia and the combined mass of small suppliers could be the limiting factor on Australia's ability to compete within the global arena.

This paper starts by briefly introducing the purpose of the study, the method used for data collection and the associated limitations of specific region and/or sector studies. Next, a background and literature based around the topics of communication and information sharing was presented. This was followed by additional information about the field of research and the sample which was chosen for collecting the data. Next, the paper presents the tests, results and analysis of the findings from the study. Finally, the conclusion and recommendation of further work were highlighted.

\section{Background and Literature}

There have been many studies regarding the importance of communication within organisational networks (Reinsch, 1991; Littlejohn and Peng 2001; Rentz, 2009; Rowan, 2011). However, there has been little work conducted on communication in the entire Australian supply base. This type of research has gained importance due to issues of globalisation, which has in turn resulted in an increase in complexity and uncertainty. Paradoxically, it would appear that, although there is an increase in "data" (i.e. low level information), true communication has decreased as a result of loosing face-to-face interaction between supply network partners (Eichenlaub and Bekmeier, 2010). When communication is successful, many benefits can occur (Daley, Nargundkar and Samaddar, 2005). In an attempt to provide some basic data concerning the Australian supply base which included the objective of better understanding the level of inter-organisational communication within Australian networks, a series of focus groups were involved in a program of work sponsored by the Australian Federal Government to support business development. The focus groups were conducted within major business centres and also regional hubs. The literature for this study covered the following areas:

1. Defining Communication

2. Communication Benefits

3. Types of Information Communicated

4. Factors Impacting Communication and Information Sharing

5. Inter-Organisational Communication Challenges

\subsection{Defining Communication}

Communication is defined by Reinsch (2001) as a verbal exchange between different individuals using commonly held symbols. This definition is however typically too simplistic and does not take into account advancements in information 


\section{Kotob \& Styger}

and communication technologies which offer the ability to communicate globally (Rowan, 2001). From a business perspective, this communication involves interacting with both internal and external players (Reinsch, 2001). This interaction is not about the simple transmission of data (Marchori and Oliveira, 2009), but rather a process of steering suppliers towards taking actions that positively support their partners (Rentz, 2009). The process starts when different parties have an understanding of what to, what not to, and how to communicate (Gollightly, 1973).

\subsection{Communication Benefits}

There are many benefits that organisations can obtain from communication. These benefits are the result of an increase in the level of information and ideas available and subsequently shared across organisations (Cheng, 2011; Bachmann and Inkpen, 2011). In the context of supply chain management, these benefits include:

1. A reduction in supply chain disruptions (Corsten, Gruen and Peyinghaus, 2011)

2. A reduction in costs leading to better economical goals (Bachmann and Inkpen, 2011; Cheng, 2011; Corsten, Gruen and Peyinghaus, 2011; Daley, Nargundkar and Samaddar, 2005; Humphries and Sculli, 2001)

3. An increase in the level of innovation (Corsten, Gruen and Peyinghaus, 2011)

4. An ability to improve decision making and competitiveness (Cheng, 2011; Hall, Ledlow, Ulijin and Weggeman, 2000; Humphries and Sculli, 2001; Li, 1997)

5. An ability to share and minimise the impacts of risks (Cheng, 2011)

6. An ability to better respond to global turbulence (Humphries and Sculli, 2001)

7. An ability to protect the reputation of the organisation (Rowan, 2011)

8. An ability to improve strategic thinking (Browne, Folan and Higgins, 2006)

\subsection{Types of Information Communicated}

The types of information that organisations communicate is divided into four main categories, these are shown in Table 1: 


\section{Kotob \& Styger}

Table 1: Types of Information Communicated

\begin{tabular}{|c|l|}
\hline \multicolumn{2}{|c|}{ Types of Information Communicated } \\
\hline $\begin{array}{c}\text { Transactional } \\
\text { Information }\end{array}$ & $\begin{array}{l}\text { Transaction information is the exchange of price and order } \\
\text { quantities using electronic data interchange (EDI). This } \\
\text { exchange does not impact on efficiency which remains the } \\
\text { responsibility of every company. }\end{array}$ \\
\hline $\begin{array}{c}\text { Operational } \\
\text { Information }\end{array}$ & $\begin{array}{l}\text { Operation information is the exchange of information which } \\
\text { can help the recipient become more efficient. The owner of } \\
\text { the data can also benefit from cost reductions within their } \\
\text { business. }\end{array}$ \\
\hline Strategic Information \\
\hline $\begin{array}{l}\text { Strategic and } \\
\text { Competitive } \\
\text { Information }\end{array}$ & $\begin{array}{l}\text { Strategic information is the exchange of information that } \\
\text { can help the recipient achieve strategic and operational } \\
\text { benefits. This information usually has minimal value to the } \\
\text { owner if not shared (i.e. sharing point of sale (POS) data } \\
\text { with partners who can use it to improve forecasts, increase } \\
\text { efficiency and reduce costs across the supply chain). }\end{array}$ \\
\hline $\begin{array}{l}\text { The exchange of strategic and competitive information } \\
\text { which could be used to achieve a competitive benefit. The } \\
\text { owner of the information gains minimal benefit from } \\
\text { sharing the information (i.e. owner of the data provides } \\
\text { sales information to their partners as well as information } \\
\text { about what their competitors are doing). }\end{array}$ \\
\hline
\end{tabular}

Source: (Daley, Nargundkar and Samaddar, 2005)

\subsection{Factors Impacting Communication and Information Sharing}

There are many factors that can impact on communication and information sharing across organisations. These are divided into the two main categories:

1. Technology

2. Other

\subsubsection{Technology}

Much of the literature concerning supply chain communication typically explores the impact of technology on communication and information sharing across organisations.

Browne, Folan and Higgins (2006) for example, discuss communication infrastructure as a mean to transfer data between business partners. For this to happen, the authors discuss an extended enterprise which focuses on integrating systems to support communication. This integration is essentials for partners to communicate successfully especially in dispersed locations (Browne, Folan and Higgins, 2006; Rowan, 2011).

Humphreys and Sculli (2001) explains how important it is for collaborating parties to use an information system for sharing and storing information across business units. This advanced technology can simplify and facilitate electronic data interchange. This is facilitated by advanced internet based applications that deliver electronic data interchange (EDI). 


\section{Kotob \& Styger}

Li (1997) named this infrastructure Information and Communication Technologies (ICT) which help in integrating businesses by using networking technologies. This allows businesses to deliver information to both close and spatially separated activities. Carbonara (2005) also talked about Information and Communication Technologies such as ERP, intranet and extranet being able to deliver a coordinated and integrated process that supports quick and easy information structuring, storage and transfer.

Cheng (2011) examined the factors that influence information sharing and talked about the importance of increasing connectedness by building channels of communication which can create opportunities to interact and assist other supply chain partners.

In a globalised environment, technology is an important tool used to share information in dispersed locations. For this to happen, technology needs to enable easy access to information by providing a user friendly platform that can be used to successfully manage communication (Rowan, 2011).

\subsubsection{Other Factors}

Generally, the literature centers on the need for technology to deliver communication and information sharing across businesses (Browne, Folan and Higgins, 2006; Carbonara, 2005; Cheng, 2011; Humphries and Sculli, 2001; Li, 1997; Rowan, 2011).

In addition to the technology aspect of communication, there are other factors that can impact on inter-organisational communication and information sharing. Typically, these factors are discounted in the literature associated with supply chain communication, yet might be more important than a basic technological communication platform. These factors include:

1. Connectedness

2. Relational benefit

3. Environmental pressures

4. Regulations

5. Goal congruence

6. Employees

7. Trust

8. Supplier to buyer investment

9. Cross cultural alignment

10.Forming common identity

\subsubsection{Connectedness}

Connectedness is the level to which organisations depend on each other when looking for assistance (Hartley and Benington, 2006). When organisations are closely connected, they engage in the process of sharing information with their partners (Cheng, 2011). 


\section{Kotob \& Styger}

\subsubsection{Relational Benefit}

Supply chain members are more willing to share information if they see that their partners are engaging in the process of building partnership and sharing benefits instead of acting opportunistically to achieve their own benefits (Cheng 2011).

\subsubsection{Environmental Pressures}

Environmental pressures are now forcing organisations, who are aiming to be sustainable, to share information with their partners. If this sharing is not forthcoming, it could negatively impact on both parties and result in their inability to compete in a global environment (Cheng, 2011).

\subsubsection{Regulations}

Laws and regulations are often being used by companies to place mandates that would force their partners to share information (Cheng, 2011). This is known as Political Economy where information gets shared to help the focal firm benefit (Humphries and Sculli, 2001).

\subsubsection{Goal Congruence}

Goal congruence between supply chain partners have an impact on the nature and amount of information that gets shared across the network. When the goals are aligned, communication partners can achieve more benefits and information sharing (Daley, Nargundkar and Samaddar, 2005).

\subsubsection{Employees}

The wisdom of employees can help organisations in sharing and benefiting from the information that technology can provide (Rowley, 2007). This is why it's important to nurture the ability of these employees, that could increase their commitment to working for the organisation and could help ensure that they become more supportive to the organisations' strategic direction (Ridder, 2004).

\subsubsection{Trust}

Creating trust between individuals who do not necessarily work for the same organisation is important to increase information sharing initiatives and transparency in both online and face-to-face communication (Corsten, Gruen and Peyinghaus, 2011). This is due to communicating partners often becoming able to form common values, languages, identities and beliefs which strengthen interactions between clusters (Carbonara, 2005).

\subsubsection{Forming Common Identity}

Organisations who share a common identity with their partners are often encouraged to share knowledge and transfer information with them. This reduces cycle time, minimises transaction costs and improves economical goals (Corsten, Gruen and Peyinghaus, 2011). 


\section{Kotob \& Styger}

\subsubsection{Supplier to Buyer Investment}

Supplier to buyer identification can positively impact on the amount of relationship specific investment undertaken. When this identification increases, trust and investments into the relationship increases which supports information exchange. This in turn increases innovation, lower costs and minimises the amount of disruption across the chain (Corsten, Gruen and Peyinghaus, 2011).

\subsubsection{Cross Cultural Alignment}

Cross cultural supply chain communication can result in aligning inter-organisational cultures (Rentz, 2009). This alignment could lead to building trust especially when communicating via email (Davis, 2009).

The literature suggests that there are two methods to drive information sharing across organisations. The first method is the Exchange Theory which focuses on building relationships voluntarily. The second method is Political Economy which is more concerned with legal mandates and regulations (Humphries and Sculli, 2001).

\subsection{Inter-Organisational Communication Challenges}

The literature presents many factors that can support communication and information sharing across organisations. However, effective communication still tends to be lacking in many supply networks. This is typically due to the following reasons:

1. There is a lack of technological compatibility across partners which inhibits the integration necessary for sharing information (Browne, Folan and Higgins, 2006)

2. Technological incompatibility leads to sharing incompatible data. Transferring that data into a usable format is costly and labour exhaustive (Browne, Folan and Higgins, 2006)

3. Globalisation has resulted in organisational capabilities being outsourced and dispersed across national boundaries. This has caused new business structures to emerge. These structures are highly reliant on sub-contracting and self employment where interactions are commercially driven and subject to change (Rentz, 2009)

4. Dispersed partners make the process of building trust needed for sharing information more difficult (Davis, 2009)

5. The adoption of Information and Communication Technologies is still low among SME'S (Carbonara, 2005)

6. Inaccurate information exchange hampers accomplishments (Davis, 2009)

7. Exercising continuous pressure on cutting costs is hampering the process of building trust and information sharing between partners (Daley, Nargundkar and Samaddar, 2005)

\section{Preliminary Field Research and Collection of the Sample Set}

In order to establish the current level of communication protocols in Australia, sample data was collected from a series of focus groups that were involved in a program of work sponsored by the Australian Federal Government to support 


\section{Kotob \& Styger}

business development. The focus groups were conducted within major business centres and also regional hubs.

The program was promoted using a series of databases and advertisements in the public electronic and print media. Participants were asked to pre-register for the regional focus group of their choice. As such, the sample set can be determined to be a random (or as near as is possible) representation of Australian business. It should be noted that each business had their own supply base and was involved in at least one traditional customer supply network, and were therefore qualified to take part in the study. Furthermore, all participants were senior officers within their organisations and as such were involved in the strategic aspects of their business, including strategic and operational aspects of their supply chain.

No qualifying participants were excluded from the study, however, there was, as would be expected, a natural filtering process from the initial contact stage to final participation. The filtration ratio was 1:64 and is consistent with recognised protocols and it is therefore considered to be a robust sample within the scope of this study. The filtration ratio is shown in Table 2.

Table 2: Study Participants Filtration Process

\begin{tabular}{|l|c|}
\hline \multicolumn{2}{|c|}{ Filtration Ratio of Study Prospects Compared to Study Participants } \\
\hline Number of open (advertising) media coverage & 7000 \\
\hline Number of prospects contacted directly & 400 \\
\hline Number of positive registrations & 235 \\
\hline Number of active participants & 109 \\
\hline Ratio of Prospects to Participants & $\mathbf{1 : 6 4 . 2 2}$ \\
\hline
\end{tabular}

The ratio of prospects to participants is consistent with Craig and Douglas (2005) and is considered to be a robust sample within the scope of this study.

The diagnostics program used was drawn from proven business modeling, analysis and due diligence methodologies. The diagnostics had been used successfully in many private business improvement consultation programs and supplier selection protocols globally (Styger, 2011).

In an effort to prove the efficacy and relevance of the study from an Australian perspective, the diagnostics were first piloted in several smaller Australian focus groups including regional industrial groups, chambers of commerce and professional service focus groups prior to being incorporated into the study. The study was conducted in an environment of an informed and inclusive network. In all cases, participants were provided with support and standard background information. The diagnostics were developed around five key themes, these were:

1. Analysing Strategic Positioning and Market Trends

2. Analysing Supply Networks, Supply Competency and Capability

3. Analysing the Potential Risk Inherent within Supply Networks

4. Analysing Technology 


\section{Kotob \& Styger}

\section{An Insight into Innovation (1 - See End Note Section)}

It should be noted that the analysis is based on the hypothesis that the focus groups provided an initial random sample of Australian business (i.e. supply base) and the mean averages of the collective focus groups is a representative and robust indicator of Australian supply base. There is no suggestion that there were not some world-class participants within the focus groups, however, it is the sample mean in this case that provides the core indicator of performance not selected "best (or indeed worst) in class"

\section{Pilot Test}

\subsection{Analysing Strategic Positioning and Market Trends}

In order to see how participants strategically thought about the role of their suppliers and customers and to understand their future sense of direction in their sector, participants took part in the following activities.

\subsubsection{Identifying the Ideal Market Position}

Participants were asked to identify how they were positioned within the supply network and what additional value their suppliers provided.

\subsubsection{Strategic Positioning of Suppliers and Customers}

Participants were provided with two pro-forma's and asked to map where their suppliers and where their customers were strategically positioned. They were also asked to note the key attributes of their suppliers.

\subsubsection{Developing a Sense of Future Sight in the Sector}

This diagnostic consisted of participants being asked to imagine what was likely to be happening within their field of operation in the near future. This exercise had been described as "developing a capacity for over the horizon planning" and participants were asked to establish an "Over The Horizon" (OTH) perspective for their organisations supply.

The results from this study are presented in section 5 .

\subsection{Analysing Supply Networks, Supply Competency and Capability}

In order to see if companies knew their supply chain and to understand their current inter-organisational communication practices aimed at delivering sustainability, participants took part in the following activities.

\subsubsection{Mapping the Supply Chain}

This diagnostic was used as the "ice breaker" to the study. Participants were asked to map their organisations supply chain using the "bow tie" model (often used to theoretically illustrate the principles of supply networks). In many respects, this should have been the simplest exercise for all of the participants, but, it was found 


\section{Kotob \& Styger}

to be one of the most difficult because many participants had never viewed their organisation from a supply perspective before.

\subsubsection{Re-mapping the Supply Chain}

Later in the study, and as confidence developed, participants were asked to remap their supply chain with key nodal links (i.e. the main transactional points of their supply network). This diagnostic occurred approximately four hours into the session. Some improvement was made, but interestingly, the depth of the supply network was lacking in most cases.

\subsubsection{Transaction and Interaction Capability within the Supply Network}

Two diagnostics exercises were used to map how the participants believed they were communicating and transacting within their networks and how well their suppliers were communicating and transacting with them. This exercise appeared to be the most challenging for many participants. Indeed, many participants wanted to be removed from the process of sales, somehow believing that is was "dirty".

\subsubsection{The Fundamental Starting Point of a Sustainable Supply Network}

This exercise was designed to get participants started in terms of developing sustainable supply networks. It consisted of six basic questions and an opportunity to develop a simple position statement or statement of intent for improvement.

The results from this study are presented in section 5 .

\subsection{Analysing the Potential Risk Inherent within Supply Networks}

In order to see if companies have an understanding on the impact of risks on their supply chain and to understand their current risk management practices, took part in the following activities.

\subsubsection{Analysing a Potential Immediate Stop in Supply}

This diagnostic asked participants to predict what could happen immediately to their business that would stop them getting the resources they needed to operate.

\subsubsection{Analysing a Potential Stop in Future Supply}

In this diagnostic, participants were asked to draw out what would happen today to stop their organisations getting the resources that they needed to operate into the future.

\subsubsection{Risk Analysis Planning}

In this diagnostic, participants were asked to develop a simple analysis profile consisting of the top five risks in their current supply chain. 


\section{Kotob \& Styger}

\subsubsection{Analysing Technological Risk}

In completing the supply chain "Sanity Check List" and the "Technology Audit", it was apparent that these concepts were foreign to most participants. The completion of these diagnostics was typically discounted by most of the participants. This may be due to an inadequacy in understanding basic supply chain concepts or diagnostic fatigue, however further investigation highlighted the disturbing trend that, whereas most senior officers of the participating companies were well aware that technology should be appropriate, efficient and accessible within their organisations, most typically outsourced the decision, control and performance measures.

The results from this study are presented in section 5.

\section{Results of the Field Research}

From the samples in this study which included senior officers involved in the strategic aspects of their business, including strategic and operational aspects of their supply chain, it may be suggested that there is a clear and present risk in the foundation base of Australian supply. This is due to the following factors that have a direct impact on current supply:

1. A critical mass of the supply base does not exist and key knowledge capital is limited and not extended throughout supply networks.

2. Many suppliers do not possess the threshold capabilities necessary to engage with current customer procurement matrices. These include common communication protocols.

3. Communication protocols at lower levels of supply chains are typically lacking.

Perversely, within the context of proven and traditional models of supplier development and procurement, business as a whole has done nothing wrong. Common wisdom has acknowledged that supply networks are complex and efficiencies and value can be added to a supply network if the Focal Company targets its effort at the first couple of tiers of supply and role shifts responsibility for managing lower tiers to its own suppliers. The rational extends to include the use of good technology (i.e. ERP) to communicate throughout the supply base. Figure 1 Illustrates the basic concept of bow tie thinking and the ERP cascade. 


\section{Kotob \& Styger}

Figure 1: The Basic Concept of Bow Tie Thinking and the ERP Cascade

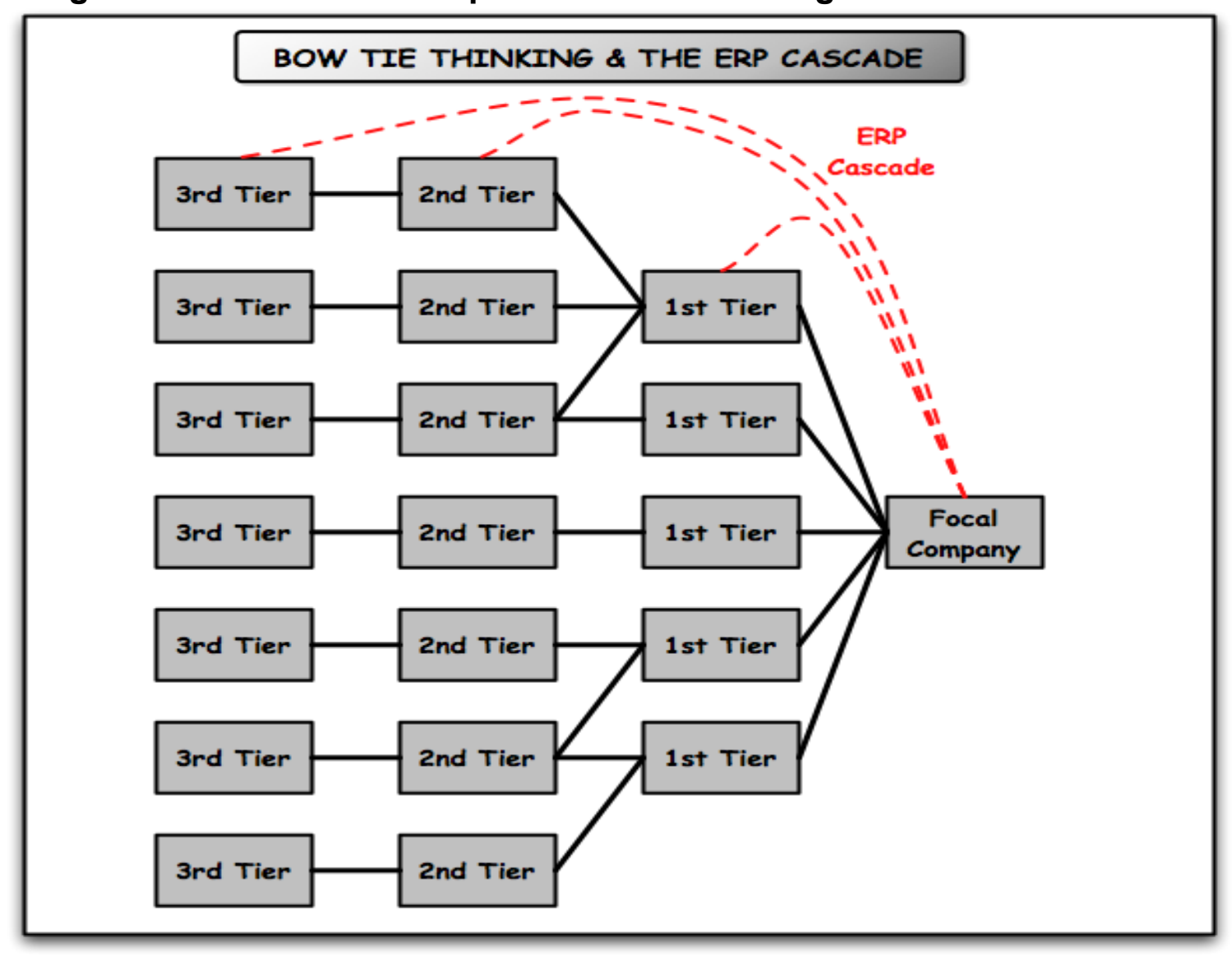

In the model of communication illustrated in Figure 1, role shifting has been extensively exploited as a principle for focusing supply management attention on "where it needs to be focused" (i.e. core, key top level suppliers). However, by taking a slightly different view of supply mapping, and effectively turning the map through $90^{\circ}$, it is possible to visualise a case where top tier suppliers (i.e. tiers 1 and 2) effectively block any view of other suppliers due to their magnitude compared with lower level suppliers. It is reasonable to assume that no amount of "Over - the Horizon" (OTH) strategy is going to impact on the current status of a supply network because the focal company cannot achieve enough levitation to see over the blockers. Figure 2 illustrates the basic concept of role shifting in the context of Over - the - Horizon thinking. 
Kotob \& Styger

Figure 2: An Illustration of Role Shifting in the Context of Over The Horizon Thinking

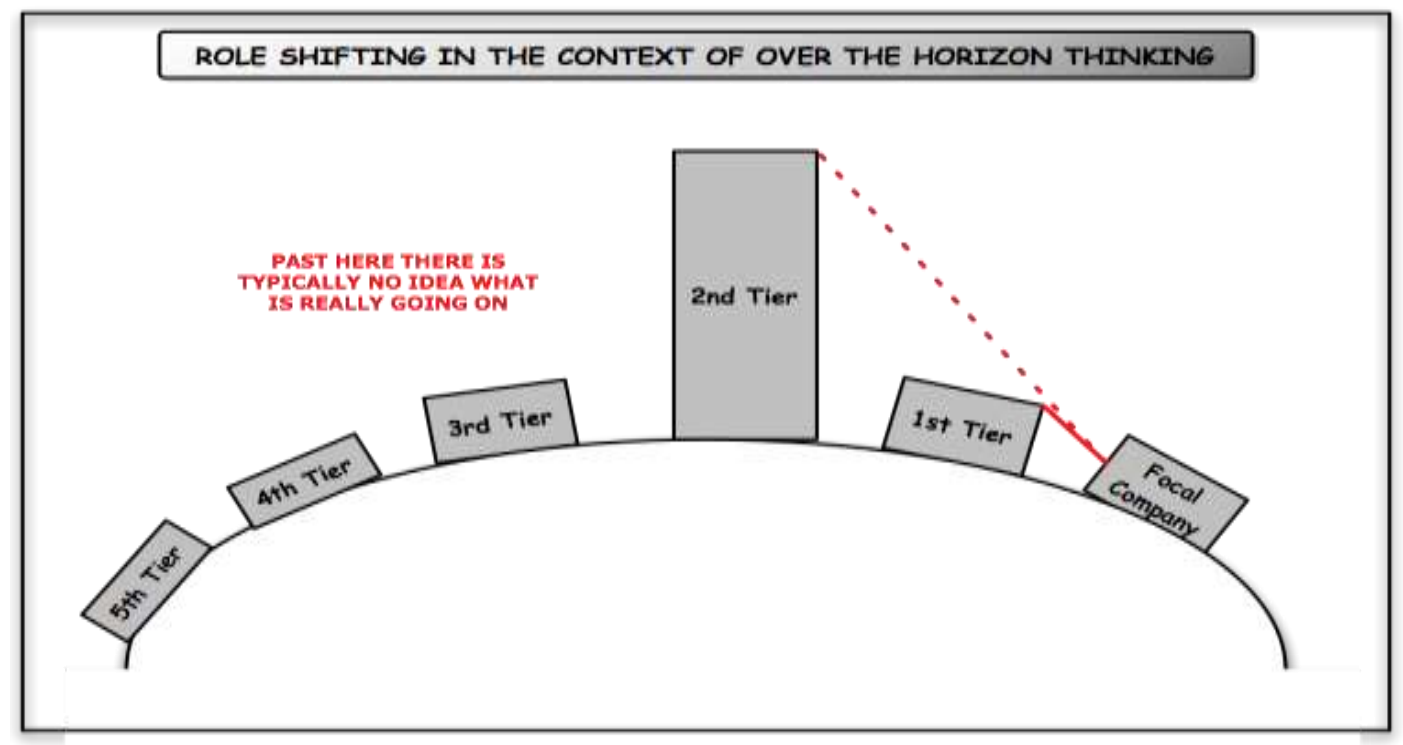

Importantly there appears to be a significant disconnect between the space that a supplier occupies within a supply network and the corresponding framework that a supplier operates within. This may be summarised within a scenario where a focal company and its local area supply network (i.e. the top tier suppliers) operate within one local active supply network and at the same point lower level suppliers operate within their own active local area supply network. A bidirectional disconnect therefore appears to exist where the focal company assumes (usually incorrectly) that someone else is taking care of other often perceived to be less important local area supply network, at the same time local area supply networks outside of the core cluster (i.e. lower tiers of suppliers) typically assume (usually incorrectly) that the focal company is their customer. A myth of supply integration is developed and a mantra set within the overall network, because it is a convenient axiom that is never challenged. Put simply there is no evidence to suggest that full supply integration has ever been established within any full supply network. Figure 3 illustrates the myth of supply integration.

Figure 3: The Myth of Supply Integration

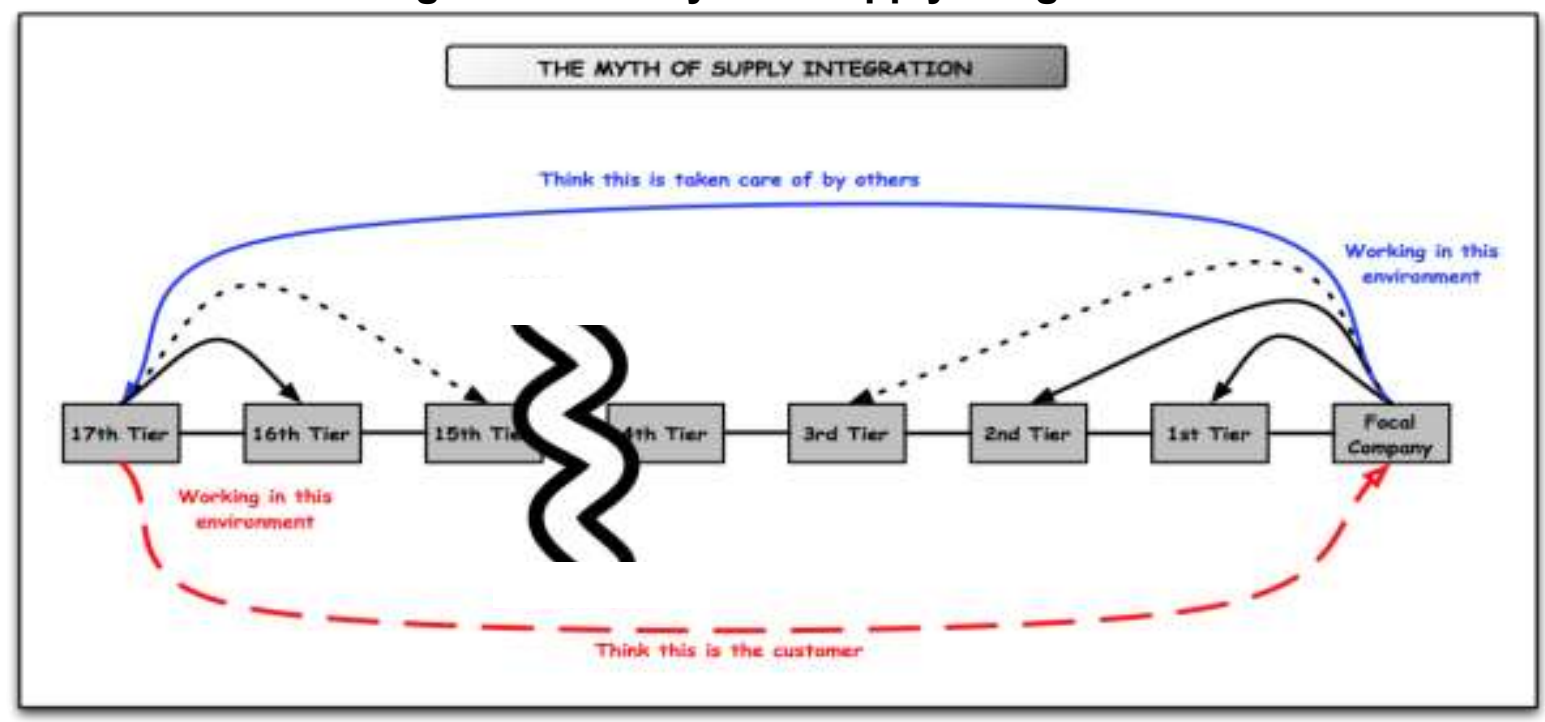




\section{Kotob \& Styger}

\section{Analysis}

Overall the sample highlighted a significant disconnect between the supply literature presenting theory and practice. Technology and people investments are typically lacking in an environment where they are essential to deliver communication and information sharing, which results in below standard supply chain performance.

Furthermore, most organisations are unable to map their supply networks further than a few core (close to home) suppliers. This means that organisations don't know, understand or monitor the risks embedded in these networks causing below standard performance. This is due to their reactive and costly approach of managing supply chain risks.

Evidence suggests that the well recognised theoretical concepts of collaboration and integration are not actually being practiced. This along with the evidence of little mid to long term planning suggests that there is a lack of strategic supply strategy to resolve the current issues of communication and risks monitoring breakdowns across the chain.

From these findings, it can be assumed that changes to current inter and intraorganisational communication and management practices are needed for the network to remain sustainable.

\section{Conclusion}

The theory presented in this paper clearly highlighted the crucial role interorganisational communication plays in helping businesses become sustainable. For this sustainability to be achieved, organisations need to invest in people, technology and trust building processes, all of which could lead to information sharing between partners. Achieving this information sharing is supported by both technological and non technological drivers which was highlighted in the many factors identified in the research.

However, a study of Australian businesses in focus group settings presented a disturbing paradox which showed that companies lack the understanding of their supply chain and have inadequate communication management practices to support their long term sustainability.

From these findings, It can be concluded that changes to current inter and intraorganisational management practices are typically needed in many Australian supply networks in order for them to remain sustainable.

\section{Recommendation for Further Work}

The recommendation for further work includes developing a model of InterOrganisational Information Sharing. This model can provide the foundation for creating a rule based framework to identify the stages that organisations can follow to achieve a successful and rewarding partnership. 


\section{Kotob \& Styger}

\section{Endnotes}

1 - Themes 4 and 5 are not relevant for this study and are not discussed in the work

\section{References}

Bachmann, R and Inkpen, A 2011, 'Understanding institutional-based trust building processes in inter-organisational relationships', Organisation Studies, vol. 32, no. 2, pp. 281-301.

Boyer, K and Verma, R 2010, Operations \& Supply Chain Management for the 21st Century, Cengage Learning, Mason, $\mathrm{OH}$

Browne, J, Folan, $\mathrm{P}$ and Higgins, $\mathrm{P}$ 2006, 'A communication framework for extended enterprise performance measurement', International Journal of Computer Integrated Manufacturing, vol. 19, no. 4, pp. 301-314.

Carbonara, N 2005, 'Information and communication technology and geographical clusters: opportunities and spread', Technovation, vol. 25, issue. 3, pp. 213222.

Cheng, J 2011, 'Inter-organisational relationships and information sharing in supply chains', International Journal of Information Management, vol. 4, issue. 3, pp. 374-384.

Corsten, D, Gruen, T and Peyinghaus, M 2011, 'The effective of supplier to buyer identification on operational performance - an empirical investigation of interorganisational identification in the automative relationships', Journal of Operations Management, vol. 29, issue. 6, pp. 549-560.

Craig, C. S and Douglas, S 2005, 'International Marketing Research', John Wiley \& Sons Ltd., West Sussex.

Daley, M, Nargundkar, S and Samaddar, S 2005, 'Inter-organisational information sharing: the role of supply network configuration and partner goal congruence', European Journal of Operational Research, vol. 174, issue. 2, pp. 744-765.

Davis, A and Dobelman, J 2009, 'An exploratory look at intercultural business communication by email', The Multinational Business Review, vol. 17, no. 1, pp. 73-99.

Eichenlaub, A and Bekmeier-Feuerhahn, S 2010, 'What makes for trusting relationships in online communication', Journal of Communication Management, vol. 14, no. 4, pp.337-355.

Finch, BJ 2008, 'Operations Now: Supply Chain Profitability and Performance', McGraw-Hill/Irwin, Boston.

Golightly, H 1973, 'The what, what not, and how of internal communication', vol. 16, issue. 6, pp. 47-50.

Hall, T, Ledlow, G, Ulijin, J and Weggeman, M 2000, 'Innovation, corporate strategy and cultural context: what is the mission for international business communication', The Journal of Business Communication, vol. 37, no. 3, pp. 293-317.

Hartley, J and Benington, J 2006, 'Copy and paste, or graft and transplant? Knowledge sharing through inter-organizational networks', Public Money \& Management, vol. 26, issue. 2, pp. 101-108.

Humphreys, P and Sculli, L 2001, 'An inter-organisational information system for supply chain management', International Journal of Production Economics, vol. 70 , issue. 3 , pp. 245-255. 


\section{Kotob \& Styger}

Kim, S and Raders, S 2010, 'What they can do versus how much they care: assessing communication strategies on fortune 500 websites', Journal of Communication Management, vol. 14, no. 1, pp. 59-80.

$\mathrm{Li}, \mathrm{F}$ 1997, 'From compromise to harmony: organisational redesign through information and communication technologies', International Journal of Information Management, vol. 17, no. 6, pp. 451-464.

Littlejohn, D and Peng, W 2001, 'Organisational communication and strategy implementary - a primary inquiry', Journal of Contemporary Hospitality Management, vol. 13, issue. 7, pp. 360-363.

Marchiori, M and Oliveira, I 2009, "Perspectives, challenges, and future directions for organisational communication research in Brazil", Management Communication Quarterly, vol. 22, no. 4, pp. 671-676.

Reinsch, L 1991, 'Editorial: What is business communication?', The Journal of Business Comunication, vol. 28, issue. 4, pp. 305-310

Rentz, K 2009, 'Making a difference with business communication', Journal of Business Communication, vol. 46, no. 4, pp.510-514.

Ridder, J 2004, 'Organisational communication and supportive employees', Human Resources Management Journal, vol. 14, no. 3, pp. 20-30.

Rowan, W 2001, 'What globalisation means for communication', Strategic Communication Management, vol. 5, issue. 6, pp.14-21.

Rowley, J 2007, 'The wisdom hierarchy: representations of the DIKW hierarcy', Journal of Information Science, vol. 33, no. 2, pp. 163-180.

Styger, L 2011, 'An Analysis of the Sustainability and the Future of Innovation Readiness within the Australian Supply Base - A Cross-Sectorial, CrossRegional Snapshot', University of Wollongong Sydney Business School, accessed 26/2/2012,

http://www.uow.edu.au/content/groups/public/@web/@gsb/documents/doc/uo w098879.pdf. 